\title{
Similarity and Scientific Representation
}

\author{
Adam Toon \\ Department of Philosophy, University of Bielefeld, P.O. Box 100 131, \\ 33501 Bielefeld, Germany \\ adam.toon@uni-bielefeld.de
}

\begin{abstract}
The similarity view of scientific representation has recently been subjected to strong criticism. Much of this criticism has been directed against a 'naïve' similarity account, which tries to explain representation solely in terms of similarity between scientific models and the world. This paper examines the more sophisticated account offered by the similarity view's leading proponent, Ronald Giere. In contrast to the naïve account, Giere's account appeals to the role played by the scientists using a scientific model. A similar move is often made by defenders of resemblance theories of depiction, who invoke the role played by the artist, or by the viewers of a painting. In this paper I look to debates over depiction to assess the difficulties facing those who wish to defend the similarity view of scientific representation. I then turn to examine Giere's account. Ultimately, I argue, this account is unsuccessful: while appealing to the role of scientists offers a promising way to defend the similarity view, Giere's own account does not capture what it is that scientists do when they use a model to represent the world.
\end{abstract}




\section{Introduction: models and representation}

There is now a growing body of work devoted to understanding scientific representation (e.g. Bailer-Jones 2003; Callender and Cohen 2006; Chakravartty 2010; Contessa 2007; Downes 2009; Elgin 2009, 2010; Hughes 1997; French 2003; Frigg 2006, 2010b; Giere 1999b, 2004, 2010; Suárez 1999, 2003, 2004; Toon 2010b, 2012; van Fraassen 2008). Although some of this work is concerned with the full range of representational devices used in the sciences, most focuses in particular on scientific models. Models may be distinguished into two types: physical and theoretical. Physical models are concrete physical objects. Examples include Crick and Watson's DNA model and the famous Phillips machine, which represents the workings of the economy by the flow of coloured water between tanks (Morgan and Boumans 2004). Examples of theoretical models are Bohr's model of the atom, the billiard-ball model of gases and Newtonian models of the solar system. It is more difficult to say what theoretical models are. Scientists engaged in theoretical modelling do not build any concrete physical object that we can identify as their model; instead, they usually simply write down a set of equations and simplifying assumptions. Despite this, most philosophical accounts take theoretical models to be non-linguistic objects, which are defined by (or merely specified by) the equations and assumptions that the scientists write down. Different authors give different accounts of the ontology of these objects. According to some (e.g. Giere 2004), theoretical models are abstract entities. Different versions of the semantic view take models to be mathematical entities such as set-theoretical structures (Suppes 1960) or trajectories through phase-space (Van Fraassen 1980). Recently, some have suggested that 
theoretical models are imaginary or fictional entities (Contessa 2010; Frigg 2010a; Godfrey-Smith 2006; see also Giere 2009; for an opposing view, see Toon 2010a, 2012).

Many physical models represent some object or event in the world. Crick and Watson's model represents the DNA molecule. The Phillips machine may be used to represent the British economy, or the French. Scientists also represent the world through theoretical modelling. The Bohr model represents the atom. The billiard-ball model of gases might be used to represent a vessel of hydrogen or helium. The problem of representation for scientific models is to understand how such cases of representation work. If one takes theoretical models to be non-linguistic objects (abstract, mathematical or fictional) then representation in both physical and theoretical modelling would seem to be non-linguistic. A number of philosophers of science have therefore looked to work on other forms of non-linguistic representation, particularly depiction (e.g. French 2003, Frigg 2006; Suárez 1999, 2003; Toon 2010b, 2012). In itself, it seems, a painting like Constable's Salisbury Cathedral From the Meadows is merely a collection of brushstrokes on a piece of canvas. And yet it depicts horses pulling a cart through a stream and the Cathedral itself beneath a rainbow. The problem for theories of depiction is to understand how it does this. In virtue of what does Constable's painting represent the Cathedral? The problem of representation for scientific models may be presented in the same way. The reconstruction of Crick and Watson's original DNA model in the Science Museum is simply a collection of metal rods and plates held in place by clamps. And yet it represents the complex helical structure of the DNA molecule. How does it do this? In virtue of what does the model represent the molecule?

A natural response to the puzzle regarding depiction is the thought that paintings 
represent their subjects because they are similar to or resemble them. Resemblance theories of depiction have a long history and enjoy considerable intuitive appeal. Similarity accounts of scientific representation share this appeal: many models possess important similarities with the systems they represent, just as many pictures resemble their subjects. Unfortunately, however, both views face significant difficulties. Nelson Goodman (1976) famously delivered a forceful critique of resemblance accounts of depiction, while Mauricio Suárez (2003) has argued that parallel problems face similarity accounts of scientific representation.

Ronald Giere has long been the most prominent proponent of the similarity account of scientific representation (e.g. 1988; 1999b; 2004; 2010). In his recent work, Giere has sought to defend the similarity account by explicitly invoking the role played by the scientists using a scientific model $(2004 ; 2010)$. The aim of this paper is to ask whether Giere's account is successful. As we shall see, appealing to agents and their representational capacities offers a promising way to defend the similarity account. Many resemblance theorists respond to Goodman's criticisms in a similar way, invoking the role played by the artist, or by the viewers of a painting. Debates over depiction will be seen to offer two further lessons, however. First, these debates show that appealing to agents is merely a first step and that we must still offer an account of exactly how it is that scientists use models to represent (Section 2). Second, the continuing debate over resemblance theories of depiction helps us to see the key challenges facing proponents of the similarity view of scientific representation (Section 3). To defend the similarity view, then, its proponents must offer a specific account of how scientists use models to represent that is able to meet these challenges. Giere's own account focuses on scientists' 
use of theoretical hypotheses, which specify the way in which a particular model is taken to be similar to the world (Section 4). Ultimately, I shall argue, this account is unsuccessful, since it fails to capture what it is that scientists do when they use a model to represent the world (Section 5).

\section{Appealing to agents}

The key to Giere's defence of the similarity account lies in his appeal to the role played by the scientists using a scientific model. Thus, Giere (2010) argues that we should adopt 'an intentional conception of representation in science that requires bringing scientific agents and their intentions into the picture' (269). In an earlier paper, Giere puts the point slightly differently, proposing a shift away from a traditional focus on 'representation' to 'the activity of representing' (2004, 743. Emphasis in original). Once again, however, the key idea is that our account should incorporate the role played by scientists and their intentions: we should focus on a relationship of the form ' $S$ uses $X$ to represent $W$ for purposes $P$ ', where $S$ may be 'an individual scientist, a scientific group, or a larger scientific community', $W$ is 'an aspect of the real world', and $X$ is a representational device (ibid.). While $X$ might be a diagram, graph, or some other form of representational device, 'it is models that are the primary (though by no means the only) representational tools in the sciences' (ibid., 747).

Let us label the kind (or perhaps kinds) of representation involved in scientific modelling model-representation. The best way to understand Giere's proposal, I think, is by drawing a distinction between two different forms an account of model-representation 
may take: derivative and non-derivative (cf. Toon 2010b, 2012). A derivative account of model-representation is one which explains how models represent in terms of some other form of representation, such as mental or linguistic representation; it shows how the representational power of models derives from some other form of representation. By contrast, a non-derivative account would attempt to explain how models represent in nonrepresentational terms. This distinction may be illustrated using accounts of depiction. According to the most straightforward resemblance theory, attacked by Goodman, 'A represents B if and only if A appreciably resembles B' (1976, 3). This account is nonderivative: it attempts to explain why a picture represents its subject in terms of the (visual) properties they share. By contrast, consider the reconstruction of Plato's account of depiction offered by Alan Goldman:

a picture represents an object if and only if (a) its artist successfully intends by marking a surface to create a visual experience that resembles that of the object, (b) such that the intention can be recovered from the experience, perhaps together with certain supplementary information, and (c) the object can be seen in the picture $(2003,194)$

This is a derivative account: it attempts to explain depiction in terms of (amongst other things) the representational capacities of certain mental states, namely the artist's intention to mark the canvas in a certain way. Without the artist and her intentions, the picture would not represent its object, however close the resemblance between them.

In this terminology, then, Giere's proposal is that we should adopt a derivative account of model-representation: his claim is that models do not represent 'on their own', 
as it were, but only because of what scientists do with them. There is sometimes a tendency to think that if scientific models are derivative forms of representation then there is no more work for philosophers of science to do. Thus, Craig Callender and Jonathan Cohen (2006) have argued that 'there is no special problem of scientific representation', since models represent in virtue of other, more fundamental, forms of representation (such as mental representation). Debates over depiction reveal this to be incorrect. Even if we believe that the representational power of pictures derives from that of mental representation, many different (derivative) accounts are open to us. For example, Kendall Walton has sought to explain depiction not through resemblance, but in terms of the particular sorts of imaginings that pictures allow viewers to engage in: what is distinctive of depiction, Walton thinks, is that the viewer imagines of her looking at the picture that it is an instance of looking at the object (Walton, 1990). This is also a derivative account: it aims to explain depiction in terms of the representational capacities of mental states (in this case, imagination). But this view is clearly very different from that offered by Goldman, and debate over the correct account of depiction continues. ${ }^{1}$

So, even if we think that the representational power of pictures derives from that of agents and their mental states, we must still offer an account of how it does so. Is it the artist's intentions that are important, for example, or the viewers' acts of imagination? What sorts of intentions or imaginings are required? Similarly, even if we think that models derive their representational status from that of scientists and their mental states, we must say exactly how they do this. What mental states are involved in bringing about

\footnotetext{
${ }^{1}$ I offer a detailed discussion of Callender and Cohen's argument in Toon (2010b, 2012).
} 
a case of model-representation and in what way? ${ }^{2}$ Or, to put the question in terms of the activity of representing: what must a scientist $d o$ in order to use a model to represent? And, in fact, there are already a number of different (derivative) accounts that we might choose here. For example, Callender and Cohen (2006), claim that all that is required for a model to represent a system is that a scientist stipulates that it does. By contrast, Mauricio Suárez's 'inferential conception' requires that a model 'allows competent and informed agents to draw specific inferences' regarding the system it represents (2004, 773). As we shall see in Section 4, Giere himself offers a rather different account, which stresses the way that scientists make use of similarities between models and the world.

How should we assess an account of model-representation? What cases should it include, and what must it exclude? Notice that, since the scientist's role may be crucial, when considering individual cases we must ask, not 'is this object a modelrepresentation?', but 'is this object-used-in-this-particular-way a model-representation?' Unfortunately, our intuitions about what counts as an instance of model-representation are rather less clear than our intuitions as to what counts as a depiction. Nevertheless, it seems that there are clear-cut cases that our account must include, like Bohr's model of the atom and Crick and Watson's DNA model. There are also clear-cut cases that any account must exclude. The most obvious are non-representational entities, like ordinary chairs, tables or trees. We must be careful here, of course. In certain circumstances, such objects may be used to represent things: a chair might appear in a play or a work of abstract art, and perhaps one might also be used as a scientific model. Such examples remind us that we must consider not only the object itself, but also the manner in which it

\footnotetext{
${ }^{2}$ Of course, we do not need to go on to provide an account of representation for mental states themselves; fortunately, this task can be left to philosophers of mind.
} 
is used. Nevertheless, in many cases (such as that of the chair I am currently sitting on) such objects are not representational in any way, and so must be excluded from our account of model-representation. A second, and slightly more controversial, set of cases we must exclude are provided by certain linguistic entities, like names. My copy of Crick and Watson's original paper contains the linguistic token 'D.N.A.'. This denotes the DNA molecule, and so may be said to represent it in one sense of the term. Yet most agree that this is not a case of model-representation. ${ }^{3}$ Perhaps the most important difference between the two is that, unlike the name 'D.N.A.', Crick and Watson's model represents the molecule as something: it 'tells us' something about the molecule, and this can be right or wrong, accurate or inaccurate.

\section{The challenge for similarity accounts}

Much criticism of the similarity view has been directed against a straightforward, 'naïve', account that can be formulated as follows (e.g. Suárez 2003; Frigg 2006):

$\left(\mathrm{S}_{1}\right): M$ model-represents $T$ if and only if $M$ is similar to $T$

Here, $M$ refers to a non-linguistic abstract (or perhaps fictional) object, in the case of theoretical models, or an actual concrete object, in the case of physical models. $T$ refers to the target system.

$S_{1}$ parallels the most straightforward resemblance theory of depiction attacked by Goodman (1976). As Suárez (2003) shows, $S_{1}$ also faces parallel problems. For example,

\footnotetext{
${ }^{3}$ An exception is Callender and Cohen (2006).
} 
similarity (like resemblance) is both symmetrical and reflexive, while representation is not. Moreover, similarity is clearly not sufficient for representation. Crick and Watson's original model might be highly similar to the Science Museum copy, but it represents the DNA molecule and not the copy.

In response to Goodman's arguments, defenders of resemblance theories have sought to amend the account in a variety of ways. Often, they invoke the role played by the artist. For example, as we saw above, Goldman includes the condition that the artist successfully intends to design the painting so that it looks like its subject. This renders the relation between a painting and its subject non-reflexive (a painting is not (usually) designed to look like itself) and non-symmetrical (the subject of the painting is not (usually) designed to look like the painting). And while a portrait of Jack might also look like his twin brother John, it is intended to look like Jack, and not John.

More sophisticated resemblance theories of depiction may therefore suggest ways in which we might we refine the naïve similarity account for models. Suárez considers an amended version of the similarity account that incorporates his notion of 'representational force' $(2003,238)$. An alternative would be to draw on the more familiar notion of denotation (cf. Goodman 1976, 6):

$\left(\mathrm{S}_{2}\right): M$ model-represents $T$ if and only if $M$ is similar to $T$ and $M$ denotes $T$

$S_{2}$ avoids many of the problems faced by $S_{1}$. The relation between model and system is now non-reflexive and non-symmetrical. And since it is no longer claimed that similarity is sufficient for representation, we may now rule out many of the 
counterexamples facing $S_{1}$ : Crick and Watson's model is similar to the Science Museum copy, but does not denote it. Of course, $S_{2}$ does not tell us how denotation is established. But the similarity theorist might reasonably defer this question to a general theory of reference. Perhaps Crick and Watson's model denoted the DNA molecule simply because they intended it to do so, or because they stipulated that it did (in which case, $S_{2}$ would be a derivative account of model-representation). However denotation is established, given that both the model and the name 'D.N.A.' denote the DNA molecule, why is only the former a model-representation of it? According to $S_{2}$, the difference is similarity. ${ }^{4}$

A number of difficulties remain, however. Again, debates in philosophy of art are instructive. Resemblance theories of depiction face two key problems: the problem of accounting for pictures with no actual object and the problem of specifying the resemblance relation. Similarity accounts of model-representation face parallels to both of these problems.

Many pictures represent no actual object (e.g. Goodman 1976; Walton 1974). There are no fairies, unicorns or vampires, and yet storybooks are full of pictures of them. Any theory of depiction must incorporate such pictures, explaining how they can be depictions even though they depict no actual object. I think the situation is analogous for theories of scientific representation. Nineteenth century physicists constructed mechanical models of the ether. Even if the ether does not exist, these models still seem to be representational. Standing in front of an ether model we want to say that it represents the ether as being at rest, for example, or as lighter than air, just as a picture of a vampire might represent him

\footnotetext{
${ }^{4}$ Of course, contemporary resemblance theories of depiction are considerably more sophisticated than $\mathrm{S}_{2}$. For a helpful discussion, see Abell (2009).
} 
as having long fangs. Our theory of scientific representation must find a way to explain such cases. ${ }^{5}$ Pictures without actual objects present a particular problem for resemblance theories of depiction since it would seem that, in order for two things to resemble each other, they must both exist. The same is true of similarity theories of modelrepresentation. If models represent in virtue of their similarity to what they represent, then what they represent must exist. Similarity accounts must therefore find some way of explaining how ether models manage to be representational, even though there is no ether.

Perhaps the most obvious and significant problems facing all similarity accounts of representation, however, are the notorious difficulties with the notion of similarity itself (see Goodman 1972). It is often remarked that anything is similar to anything else in some respect or other. Without some restriction of the similarity relation, then, even the supplemented version of the similarity account $\left(\mathrm{S}_{2}\right)$ will not provide sufficient conditions for model-representation (cf. Suárez 2003; Frigg 2006; Giere 1999b and Teller 2001). There are many representational devices which denote and are similar to their subjects in some sense or other, and it seems we would not want to class them all as modelrepresentations. 'Word' denotes 'worm', and is similar to it, but it is not modelrepresentation of it (cf. Elgin 1992). With sufficient ingenuity we may even find properties shared by the linguistic token 'D.N.A.' in my copy of Crick and Watson's paper and the DNA molecule: both are smaller than $5 \mathrm{~cm}$, both contain carbon, both are referred to in this sentence, and so on. But our intuition remains that Crick and Watson's model and the name 'D.N.A.' represent the molecule in very different ways.

\footnotetext{
${ }^{5}$ I offer a defence of this view in Toon $(2010 b, 2012)$. Models without actual objects are also discussed in Suárez (2004) and Callender and Cohen (2006).
} 
Resemblance theories of depiction face a parallel problem. A Constable painting of Marlborough Castle resembles the Castle, but it may also resemble a child's sandcastle or a pile of autumn leaves. Conversely, paintings bear many striking dissimilarities to their subjects: they are (usually) flat, rectangular, composed of paint, and so on (cf. Goodman 1976) . The task for the resemblance theorist, then, is to specify the exact sense in which a painting resembles its subject. ${ }^{6}$ Similarly, it seems that proponents of the similarity account of scientific representation must identify a similarity shared by all models and the systems they represent, in virtue of which the models represent those systems. ${ }^{7}$ Given the enormous variety of scientific models, this task would seem as daunting as that facing the resemblance theorist of depiction (cf. Suárez 2003; Downes 2009). Indeed, it may be even more daunting, for in the case of paintings, we know at least that we are searching for some visual property they share with their subjects and we have some firm intuitions about what form this resemblance takes. What common similarity could exist between, say, Crick and Watson's model and the DNA molecule, and the Phillips machine and the economy $?^{8}$

Specific problems arise when we consider theoretical models. As we saw in Section 1, Giere takes models to be non-linguistic abstract objects. Thomson-Jones (2010) has questioned whether such objects may possess the spatiotemporal properties that we appear to attribute to them. Such concerns might lead us to ask whether such objects are

\footnotetext{
${ }^{6}$ Note that not all resemblance theories claim that one form of resemblance is common to all depictions (see, for example, Abell 2009). I am grateful to an anonymous referee for pressing this point.

${ }^{7}$ As we shall see, Giere's account avoids this challenge by requiring that the relevant similarities are specified on a case-by-case basis in theoretical hypotheses.

${ }^{8}$ Isomorphism accounts of representation may be seen as offering one answer to this question (e.g. French 2003). Critics of isomorphism include Suárez (2003) and Frigg (2006).
} 
really similar to the systems they model (cf. Hughes 1997, 330). More recently, Giere has expressed sympathy with the view that models may be ontologically 'on a par' with fictional entities $(2009,249)$. Of course, given the notorious difficulties surrounding fictional entities this suggestion does not, in itself, get us very far. In another way, however, the task facing proponents of the similarity account for scientific models may be easier than that which faces resemblance theorists of depiction. In large part, what makes the resemblance theorist's task so difficult is the intuition that even Impressionist landscapes and political cartoons share a common form of representation, namely depiction. There may not be one form of representation common to all models. The similarity theorist might therefore attempt to identify a similarity common only to some subset of scientific models, although the scope of the account would be reduced accordingly.

\section{Giere's account: models and theoretical hypotheses}

Having considered the challenges facing proponents of the similarity view, let us now turn to examine Giere's own account. As we saw earlier, Giere argues that our theory of scientific representation should incorporate the way that scientists use models to represent the world. We also saw, however, that this general view is compatible with many different, derivative accounts of model-representation. Giere offers one such account, which stresses the way in which scientists exploit similarities between models and the world. He introduces this account as follows:

How do scientists use models to represent aspects of the world? What is it 
about models that makes it possible to use them in this way? One way, perhaps the most important way, but probably not the only way, is by exploiting similarities between a model and that aspect of the world it is being used to represent. Note that I am not saying that the model itself represents an aspect of the world because it is similar to that aspect. There is no such representational relationship. Anything is similar to anything else in countless respects, but not anything represents anything else. It is not the model that is doing the representing; it is the scientist using the model who is doing the representing. One way scientists do this is by picking out some specific features of the model that are then claimed to be similar to features of the designated real system to some (perhaps fairly loosely indicated) degree of fit. It is the existence of the specific similarities that makes possible the use of the model to represent the real system in this way. (Giere $2004,747-8)$

Giere calls statements specifying the similarities between model and system theoretical hypotheses. These have the form: 'Such-and-such identifiable real system is similar to a designated model in indicated respects and degrees' $(1988,81)$. For the Newtonian model of the solar system, for example, the theoretical hypothesis might read: 'The positions and velocities of the earth and moon in the earth-moon system are very close to those of a two-particle Newtonian model with an inverse square central force' (ibid.).

In Giere's view, then, a model does not represent some system simply because it is similar to it; instead, scientists must use the model to represent the system. And he offers an account of one way in which scientists do so: they exploit similarities between the 
model and system by forming theoretical hypotheses that specify those similarities. Moreover, the scientists do so for certain purposes. We might write this account as follows:

$\left(\mathrm{S}_{3}\right): M$ model-represents $T$ if a scientist(s) $S$ exploits similarities between $M$ and $T$ by forming theoretical hypotheses specifying these similarities, for purposes $P$

$\mathrm{S}_{3}$ is clearly different to the naïve similarity account $\left(\mathrm{S}_{1}\right)$. It is also very different from our amended account $\left(\mathrm{S}_{2}\right)$, even though both appeal to scientists and their representational capacities. $\mathrm{S}_{2}$ appealed to scientists in order to establish the denotation relation between model and target; the scientist might achieve this merely by saying 'let this represent that'. According to $S_{3}$, the scientist does something rather different, specifying in detail the similarities that are taken to hold between model and system, and the degree to which they do so. The scientist also plays a role in determining the purposes, $P$, which the model is being used for. Giere does not try to give an exhaustive list of the purposes models may be used for, but instead offers some examples. These include 'the general purpose of learning what something is like', such as Watson's goal of discovering the structure of DNA, as well as more specific purposes, such as investigating Brownian motion or the behavior of water flowing through pipes $(2004,749)$.

Giere develops his view principally as an account of representation for theoretical models, understood as non-linguistic abstract (or perhaps fictional) objects. What about physical models? In recent work, Giere suggests that his 'account of using abstract models to represent real systems applies as well to physical models' $(2004,748)$. 
Similarly, he argues that

[an] advantage of invoking similarity as the desired relationship between models and the world is that one's understanding of both abstract and concrete models (e.g., Watson's tin and wire model of DNA) is the same. No separate account of representation using concrete models is required. (2010, 274)

Both Giere (1999a) and (1999b) appear to widen the scope of the account still further, to cover maps and diagrams. ${ }^{9}$

At times, however, Giere adopts a different view of physical models. According to this alternative account, physical models or diagrams play the same role as linguistic expressions do in his view, of merely defining abstract models. It is the abstract model which then represents the world. Thus, in Science Without Laws (1999a) he writes that '[m]odels may also be characterised, often only partially, using non-linguistic means, such as diagrams or physical scale models' (73. Emphasis added.). Similarly, in an earlier discussion of Crick and Watson's model, Giere suggests that the

scale model provides a satisfactory means of defining a theoretical model. [...] Watson's hypothesis was that actual DNA molecules are very similar in composition and structure to the theoretical model. In practice, of course, Watson and Crick referred directly back to the scale model without explicitly invoking the theoretical intermediary. $(1985,91)$

\footnotetext{
${ }^{9}$ This interpretation of Giere is followed by Downes (2009).
} 
This is an interesting suggestion. However, if we were to take the view that diagrams or scale models do not represent the world directly, but instead by defining theoretical models, it seems we would have to say more about how this occurs. For example, how does a scale model made of wire, metal and cardboard 'define' a theoretical model consisting of an 'idealized nucleic acid with idealized subunits composed of idealized individual atoms in very specific spatial arrangements'? (ibid.) Or again, how does a diagram consisting of a line with a blob on the end constitute 'a particular embodiment of the abstract model of a simple pendulum'? $(1996,275)$ It seems clear that any account of representation for physical models or scientific diagrams that did not address these questions would remain significantly incomplete. In what follows, then, I shall set this alternative aside in favour of Giere's more recent view, that physical models are used to represent the world directly.

\section{$5 \quad$ Assessing Giere's account}

Giere argues that, by invoking the role played by scientists, his account is able to avoid the difficulties normally taken to confront similarity accounts $(2004 ; 2010)$. And, in fact, Suárez (2003) agrees that appealing to agents would counter many of his arguments against the similarity view. As I argued in Section 2, however, much depends upon the exact way that we appeal to agents and the particular role that we ascribe to them. In Section 3 we saw that this is also true of similarity accounts in particular: our amended similarity view $\left(\mathrm{S}_{2}\right)$ also appeals to agents and their representational capacities, but it is very different to Giere's account. And, of course, despite its appeal to agents, $\mathrm{S}_{2}$ still faced serious problems. Thus far, Giere's account has been subject to surprisingly little 
scrutiny. In the remainder of this paper, then, I want to ask whether the account is successful.

First, however, it is worth noting that Giere's account of how models are used to represent seems rather at odds with the considerable emphasis he places on the importance of understanding scientific representation as non-linguistic. Giere argues that his model-based account of science may sidestep longstanding problems for realism, particularly concerning the reference of theoretical terms, since in his view

the empirical representational relationship is not directly between statements and the world, but between models and the world. Here the operative notion is not truth, but similarity, or "fit," between a model and the world. (1999a, 73)

As we have seen, however, Giere's own account of how models represent makes this dependent upon a certain form of linguistic representation, namely, theoretical hypotheses: a model represents a certain system partly in virtue of a set of theoretical hypotheses detailing its similarity to that system. This makes it difficult to see how we can avoid problems concerning linguistic representation. In Giere's account, Crick and Watson use their model to represent the DNA molecule by forming theoretical hypotheses which specify the similarities between the two, with the goal of understanding the structure of DNA. Whether the model represents the DNA molecule therefore depends upon whether the terms that appear in these theoretical hypotheses, such as 'base pairs', 'bonding angles', or 'DNA' successfully refer. As a result, it seems that philosophical worries about the reference of theoretical terms will re-appear. 
A similar criticism of Giere's account has been made by Anjan Chakravartty (2001). Chakravartty argues that Giere, along with other supporters of the semantic view of theories, cannot avoid traditional problems facing scientific realism since

[a] model can tell us about the nature of reality only if we are willing to assert that some aspect(s) of the model has a counterpart in reality. That is, if one wishes to be a realist, some sort of explicit statement asserting a correspondence between a description of some aspect of a model and the world is inescapable. (330)

The point I am making is a little different. Unlike Chakravartty, I do not want to argue that realism requires statements of correspondence between descriptions of models and the world. I am not claiming that it is impossible to formulate scientific representation and realism in non-linguistic terms. The point is simply that, unlike other possible accounts of model-representation (such as $S_{1}$ or $S_{2}$ ), Giere's view explicitly invokes a form of linguistic representation. As a result, even if one rejects Chakravartty's claim that realism requires assertion, it is hard to see how Giere's account can avoid problems with the reference of theoretical terms.

Of course, even if it means we cannot sidestep traditional problems for realism, this need not lead us to reject Giere's view. So let us put this point aside and turn now to assess the account. Since it requires that the relevant respects and degrees of similarities should be specified in each case by a theoretical hypothesis, $S_{3}$ seems to evade concerns about the vagueness of similarity relations that we encountered in Section 3. Furthermore, since $S_{3}$ proposes only sufficient, and not necessary, conditions for model-representation, 
it might also avoid the difficulties posed by models that represent no actual object, like ether models, leaving such cases to be explained according to some other account. At times, Giere has even expressed scepticism regarding whether it is possible to give necessary and sufficient conditions in describing scientific modelling, suggesting instead that his account itself be viewed as an idealised model of this practice (personal correspondence). In what follows, then, we will confine ourselves to central, rather than esoteric, cases of modelling, and ask only that the account exclude the sorts of clear-cut cases discussed in Section 2, such as names and non-representational entities. Even if we give up the search for necessary and sufficient conditions, it seems that, if our account is unable to exclude cases like these, then we might question whether it has captured what is happening in model-representation.

Unfortunately, I think that it is clear that $\mathrm{S}_{3}$ is unable to exclude such cases. To see this, consider two cars taken from the same production line. Such examples present problems for the naïve similarity account $\left(S_{1}\right)$, since that account claims that similarity is sufficient for representation. According to $\mathrm{S}_{3}$, similarity alone is not sufficient for modelrepresentation. Instead, scientists must exploit the relevant similarities by forming theoretical hypotheses, and they do so for particular purposes, such as that of learning about a part of the world. Let us suppose, then, that we are in the showroom inspecting car A, and our interest turns to car B. We consult the salesperson and she tells us that we needn't bother inspecting car B because it came off the same production line. We therefore satisfy our curiosity by forming the following 'theoretical hypothesis':

$\left(\mathrm{H}_{1}\right)$ : Car B is similar to car A in its engine size, fuel mileage, top speed, and 
so on.

According to $\mathrm{S}_{3}$, car A would now qualify as a model-representation of car B; we would be using car A to represent car B. But this, I suggest, is clearly incorrect. In the scenario described, neither car is representational. When we formulate our theoretical hypothesis in order to learn about car B we do not thereby use one car to represent the other. One way to see this is to notice that, in this case, neither car is even being used to denote or refer to the other. As we noted earlier, our intuitions regarding scientific representation are certainly far from clear. But almost all are agreed that, in order to represent some target system, a model must denote or refer to it (e.g. Contessa 2007, Elgin 2009, Frigg 2010b, Hughes 1997, Suárez 2004). In the circumstances described, neither car denotes or refers to the other. Instead, they are simply relata in a set of similarity claims.

This would seem to be a serious problem for the account. There are many cases in which we simply compare two objects in order to find out about their properties, but these are not thereby cases of representation. A natural objection to make to this criticism is to point out that we could use one car to represent the other if we wanted to. This may well be true, but it misses the point of the criticism. The point is not that car A could never be used as a representation of car $B$; the point is that $S_{3}$ does not describe sufficient conditions for using the car in this way. The conditions proposed by $S_{3}$ are met even in cases where we simply compare the two cars for certain epistemic purposes, and these are not cases of representation. Even if we think it is impossible to give necessary and sufficient conditions for scientific representation, it still seems that our account should be able to distinguish between genuine cases of representation and acts of comparison like these. 
One obvious way to try to amend $S_{3}$ would be simply to add the condition that the model denotes the target system. Defending their view that stipulation is sufficient for representation, Callender and Cohen (2006) claim that Giere's recent exposition of his view, and Paul Teller's defence of it, can be read

in a way that ends up anticipating the view we are defending. For, while they [Teller and Giere] claim that $x$ represents $y$ in virtue of a similarity between $x$ and $y$, they also insist that there is no substantive sense of similarity that unites all vehicle, target pairs and that can be specified in advance. Rather, on their view, the relevant similarity relation is stipulated by users of the representations, according to their own purposes, on a case by case basis.

If this is right then our disagreement with Teller and Giere is largely terminological. Our reason for preferring our own terminology is only that, insofar as the sense of 'similarity' is entirely given by stipulation on a case by case basis, it seems that representation is only nominally constituted by similarity. What does the real representational work, it turns out, is stipulation. (77)

We must be careful to distinguish between two different acts of stipulation that scientists might carry out, however. One is the stipulation of similarities between model and system in theoretical hypotheses. Another is the stipulation that the model represents the system. In the second case, the scientist simply says 'let this represent that'. It is this second act of stipulation that Callender and Cohen claim is sufficient for model-representation. While 
an act of stipulation like this may be sufficient for denotation, most agree that it is not sufficient for model-representation. And we have just seen that stipulating the similarities between model and object is also not sufficient for model-representation. But perhaps these two acts of stipulation are sufficient if taken together?

It is possible to read Giere himself as endorsing an account along these lines. Thus, when introducing his view in the passage quoted above, Giere writes that scientists use models to represent 'by picking out some specific features of the model that are then claimed to be similar to features of the designated real system' $(2004,747$. Emphasis added). This is ambiguous as it stands. There is, of course, a sense in which the theoretical hypotheses designate the system. But we might also require that the model designate the system. Understanding designation as denotation gives us the following account:

$\left(\mathrm{S}_{4}\right): M$ model-represents $T$ if a scientist(s) $S$ uses $M$ to denote $T$ and exploits similarities between $M$ and $T$ by forming theoretical hypotheses specifying these similarities, for purposes $P$

One way in which denotation might be established is through stipulation. In this case, the account $\left(\mathrm{S}_{4}\right)$ claims that, given certain purposes $P$, the two acts of stipulation discussed above are jointly sufficient for model-representation.

$\mathrm{S}_{4}$ thus combines the conditions offered by $\mathrm{S}_{2}$ and $\mathrm{S}_{3}$. Despite this, I think, $\mathrm{S}_{4}$ still does not provide us with sufficient conditions for model-representation. To see this, suppose we are looking for a vivid way to illustrate the number of atoms involved in a 
certain chemical reaction, so we take a handful of blocks from a child's construction kit at random and say 'let this block stand for methane, this one for hydrogen, this one for chlorine' and so on. And let us assume that, as a result, the blocks denote methane, hydrogen, chlorine, etc. So far, it seems, we have a case of mere denotation, not modelrepresentation; we are using the blocks merely as convenient objects to denote the various atoms and molecules. But now suppose that someone were to point out that the block we had happened to pick for methane was tetrahedral and so has the same shape as the bonds within the methane molecule. This suggests the possibility of using the block in a different way, as something like a (very rough) scale model of methane. Using the block in this way would be a case of model-representation: we would be using the block not merely to stand for the molecule, but to represent it as tetrahedral. The important point to notice, however, is that merely asserting the similarity between the block and the molecule does nothing in itself to change the way that the block is being used to represent. We might perfectly well assert, and even write down, the similarity between the two and yet still continue using the block as before, as merely a convenient object to stand for the molecule. Clearly, what must change is our interpretation of the block: we must begin to interpret it in the way that we interpret scale models, and not merely as an arbitrary stand in for the molecule.

While this may seem an obvious point, it is easy to overlook. One reason for this, I think, has to do with the tendency I mentioned earlier, to think that once we shift our attention to the activity of representing, we need no longer worry about how exactly models gain their representational status. Another reason is that using things as models comes so naturally to us. Once the similarity between the shape of the block and the 
methane molecule is pointed out, it may be almost inevitable that we will begin to interpret the block as something like a scale model of the molecule. And, of course, we understand intuitively what it means to interpret an object in this way. It means, for example, that whereas previously we took the shape of the block to be irrelevant, we now understand it to be representational: we take it to represent the shape of the molecule. On the other hand, we still assume that other properties of the block are not to be understood as representational, such as its colour. Nevertheless, our theory of scientific representation must explain exactly how this and other, much more complicated, cases of representation work.

There are already a number of different accounts that we might draw on here. For example, following Gabriela Contessa (2007), we might say that, when interpret the block in this way, we not only take the block as a whole to denote the molecule, but also take parts of the block (say, the corners) to stand for parts of the molecule (the hydrogen atoms), and relations between the block's parts (say, between the centre and corners) to stand for relations between parts of the molecule (the carbon-hydrogen bonds). Alternatively, according to the make-believe view of models that I have offered elsewhere (e.g. 2012), when we use the block as a model we understand ourselves as being asked to imagine things according to certain rules, such as the rule that, if the block has a certain shape, then the molecule also has that shape. I do not want to defend either of these accounts of interpretation here. For present purposes, the important point is simply that, in order to use the block as a model, we must change our interpretation of it, and specifying the block's similarity to the molecule is not enough to bring about that change. The problem facing $\mathrm{S}_{4}$ is thus seen to be essentially the same as that which faced our original 
interpretation of Giere's account, $\mathrm{S}_{3}$ : forming theoretical hypotheses does nothing to change the representational status of the objects concerned. Or, to put it another way, it does nothing to change the way in which an object is being used to represent. The car remains (just) a car and the block remains (just) a useful stand in for methane.

Notice that I do not wish to argue that similarities are unimportant in modelling, or that it is impossible to defend the similarity view by appealing to the role played by scientists. I also do not want to claim that there is no role for theoretical hypotheses in scientific modelling. For example, hypotheses specifying similarities between models and the world certainly influence the way that scientists build or choose their models in the first instance: clearly, it is only because we think the block and molecule have a similar shape that we decide to interpret it as a model of the molecule. And once scientists are using a model to represent a certain system, they might formulate theoretical hypotheses to specify how good or accurate they take the model to be. All I have tried to show is that formulating theoretical hypotheses specifying similarities between a model and system, even for epistemic purposes, is not enough to use a model to represent that system, and thus bring about an instance of model-representation. If we want to understand how scientists use models to represent, and thus give models their representational properties, then theoretical hypotheses would seem to be the wrong place to look.

\section{Conclusion}

The key difference between the naïve similarity account and Giere's more sophisticated version of the similarity view is his appeal to the role played by scientists. 
As I have tried to show, appealing to agents and their representational capacities is not enough in itself. Instead, we must describe how it is that scientists use models to represent, and so establish an instance of model-representation. Giere offers one such description: in his view, scientists use models to represent by exploiting similarities between models and the world using theoretical hypotheses for certain purposes. I have argued that this account faces a number of problems. As well as being at odds with Giere's aim of avoiding traditional problems with scientific realism, it does not capture what is happening when scientists use a model to represent. While looking to the role played by scientists is a promising way to defend the similarity view, then, it seems that its proponents must offer a different account of how similarities are put to work in scientific representation. 


\section{Acknowledgements}

I am grateful to Martin Carrier, Stacie Friend, Roman Frigg, Ulrich Krohs, Martin Kusch,

Tim Lewens, Chris Pincock, Mauricio Suárez, Paul Teller, Torsten Wilholt, and especially

Ronald Giere, for extremely instructive discussion and correspondence on earlier versions of this paper.

\section{References}

Abell, C. (2009). Canny Resemblance. The Philosophical Review 118, 183-223.

Bailer-Jones, D. (2003). When scientific models represent. International Studies in the Philosophy of Science 17, 59-74.

Callender, C. and Cohen, J. (2006). There Is No Special Problem About Scientific Representation. Theoria 55, 7-25.

Chakravartty, A. (2001). The Semantic or Model-Theoretic View of Theories and Scientific Realism. Synthese 127, 325-45.

(2010). Informational versus functional theories of scientific representation.

Synthese 172, 197-213.

Contessa, G. (2007). Scientific Representation, Interpretation and Surrogative Reasoning. Philosophy of Science 74, 48-68.

(2010). Scientific Models as Fictional Objects. Synthese 172, 215-29. 
Downes, S. (2009). Models, Pictures and Unified Accounts of Representation: Lessons from Aesthetics for Philosophy of Science. Perspectives on Science 17, 417-28.

Elgin, C. (1992). Depiction. In D. Cooper (Ed.) A Companion to Aesthetics (pp113-116). Oxford: Blackwell.

— (2009). Exemplification, Idealization, and Scientific Understanding. In M. Suárez (Ed.) Fictions in Science: Philosophical Essays on Modeling and Idealization (pp77-90). New York: Routledge.

(2010). Keeping things in perspective. Philosophical Studies 150, 3 (4): 439-47.

French, S. (2003). A Model-Theoretic Account of Representation (Or, I Don't Know Much about Art . . . but I Know It Involves Isomorphism). Philosophy of Science 70, $1472-83$.

Frigg, R. (2006). Scientific Representation and the Semantic View of Theories. Theoria $55,49-65$.

- (2010a). Models and fiction. Synthese, 172(2), 251-268.

- (2010b). Fiction and Scientific Representation. In R. Frigg \& M. Hunter (Eds.) Beyond Mimesis and Convention: Representation in Art and Science (pp. 97-138).

Dordrecht: Springer.

Giere, R. (1985). Constructive Realism. In P. Churchland and C. A. Hooker (Eds.), Images of Science: Essays on Realism and Empiricism, with a Reply from Bas C. van 
Fraassen (pp75-98). Chicago: University of Chicago Press.

(1988). Explaining Science. Chicago: University of Chicago Press.

(1996). Visual Models and Scientific Judgement. In B. S. Baigrie (Ed.), Picturing Knowledge: Historical and Philosophical Problems Concerning the Use of Art in Science (pp269-302). Toronto: University of Toronto Press.

_ (1999a). Science Without Laws. Chicago: University of Chicago Press.

_ (1999b). Using Models to Represent Reality. In L. Magnani, N. J. Nersessian, and P. Thagard (Eds.), Model-Based Reasoning and Scientific Discovery (pp41-57).

Dordrecht: Kluwer Academic/Plenum Publishers.

- (2004). How Models are Used to Represent Reality. Philosophy of Science 71, $742-52$

_ (2009). Why Scientific Models Should Not Be Regarded as Works of Fiction. In Suárez (2009), (pp248-58).

- (2010). An agent-based conception of models and scientific representation.

Synthese 172, 269-81.

Godfrey-Smith, P. (2006). The strategy of model-based science. Biology and Philosophy $21,725-40$.

Goldman, A. (2003). Representation in Art. In J. Levinson (Ed.), The Oxford Handbook of 
Aesthetics (pp192-210). Oxford: Oxford University Press.

Goodman, N. (1972). Seven Strictures on Similarity. In his Problems and Projects (pp437-47). Indianapolis and New York: Hackett Publishing.

— (1976). Languages of Art. Indianapolis and New York: Hackett Publishing.

Hughes, R.I.G. (1997). Models and Representation. Philosophy of Science 64, SS325-36.

Morgan, M. and Boumans, M. (2004). Secrets Hidden by Two-Dimensionality: The Economy as a Hydraulic Machine. In S. de Chadarevian and N. Hopwood (Eds.), Models: The Third Dimension of Science (pp.369-401). Stanford: Stanford University Press.

Suárez, M. (1999). Theories, Models, and Representations. In Magnani et al. (1999), (pp75-83).

(2003). Scientific representation: against similarity and isomorphism.

International Studies in the Philosophy of Science 17, 225-44

(2004). An Inferential Conception of Scientific Representation. Philosophy of Science 71, 767-79.

Suppes, P. (1960). A comparison of the meaning and use of models in mathematics and the empirical sciences. Synthese 12, 287-300.

Teller, P. (2001). Twilight of the Perfect Model Model. Erkenntnis 55, 393-415 
Thomson-Jones, M. (2010). Missing Systems and the Face Value Practice. Synthese 172, 283-99.

Toon, A. (2010a). The Ontology of Theoretical Modelling: Models as Make-Believe. Synthese 172, 301-15.

— (2010b). Models as Make-Believe. In R. Frigg and M. Hunter (Eds.), Beyond Mimesis and Convention: Representation in Art and Science (pp71-96). New York: Springer-Verlag.

- (2012). Models as Make-Believe: Imagination, Fiction and Scientific Representation. Basingstoke: Palgrave Macmillan.

van Fraassen, B. (1980). The Scientific Image. Oxford: Clarendon Press.

B. (2008). Scientific Representation: Paradoxes of Perspective. Oxford: OUP.

Walton, K. (1974). Are Representations Symbols? The Monist 58:2, 236-54 (1990). Mimesis as Make-Believe. Cambridge, Mass.: Harvard University Press. 